\title{
Concepções e práticas de adolescentes do sexo masculino sobre sexualidade
}

\author{
Maria Juracy Filgueiras Toneli ${ }^{1}$ \\ Daniela Mendes \\ Mariana Barreto Vavassori \\ Thais Guedes \\ Ivana Finkler
}

\begin{abstract}
Resumo
Este trabalho resulta de pesquisa realizada em Florianópolis, que investigou as significações atribuídas por adolescentes do sexo masculino à vida sexual e reprodutiva. Com o objetivo de aprofundar os temas abordados mediante questionário $(\mathrm{n}=241)$, na etapa inicial foram entrevistados doze estudantes de escolas públicas e privadas do nível médio. As entrevistas semi-estruturadas obedeceram aos seguintes eixos temáticos: relacionamento familiar, representações de gênero, sexualidade, prevenção Dsts/Aids/gravidez. O material obtido foi submetido à análise de conteúdo temático e os resultados indicaram a manutenção de posições conservadoras quanto às representações de gênero, homossexualidade, gravidez na adolescência e valores familiares.

Palavras-Chave: Adolescência; Sexualidade; Saúde reprodutiva; Gênero.
\end{abstract}

\section{Meanings and practices of male adolescents about sexuality}

\begin{abstract}
This work is based on a research accomplished at Florianópolis, which aims to investigate the meanings that adolescents attributes to the sexual and reproductive life. To make more intensive study of the themes investigated by questionnaire $(\mathrm{n}=241)$ in the preliminary survey, twelve male adolescent students (private and public high schools) were interviewed. The main themes investigated were familiar relationship, gender representations, sexual life, STD/SIDA/pregnancy prevention. By a thematic content analysis (longitudinal and transversal) the results suggested a maintenance of traditional positions concerning with gender representations, homosexuality, pregnancy in adolescence and familiar values.
\end{abstract}

Keywords: Sexuality; Adolescence; Reproductive health; Gender.

Este artigo é resultante da segunda etapa de pesquisa, que teve como objetivo principal investigar como os adolescentes do sexo masculino estão vivenciando e significando suas práticas sexuais e reprodutivas. Considera-se que investigações deste tipo podem ser úteis para os programas de saúde e educação, exatamente por focarem as significações que sustentam os comportamentos. Conforme afirmam Rios, Pimenta, Brito, Terto Jr. e Parker (2002, p. 48), mencionando análise realizada por Monteiro em entrevista aos autores, propostas de intervenção voltadas para as populações jovens devem "partir do entendimento da lógica que rege o comportamento dos indivíduos e grupos", superando a perspectiva prescritiva e normativa que impera neste campo. Foi em busca da identificação dessa lógica que se realizou a pesquisa que deu origem ao presente trabalho.

Adota-se aqui a concepção de saúde e direitos reprodutivos que, de acordo com Matamala (1998), enfatiza a perspectiva de saúde integral, de atenção às dimensões biológica, psicológica e social dos sujeitos, trazendo ao âmbito dos direitos humanos o direito ao

Endereço para correspondência:

${ }^{1}$ E-mail: juracy@cfh.ufsc.br exercício pleno da sexualidade e da reprodução. Destaca-se, como marco principal neste campo, a Conferência Internacional de População e Desenvolvimento, realizada no Cairo, em 1994, por ter proposto a superação da abordagem em saúde reprodutiva que enfatiza o controle da natalidade, além de ter reconhecido a sexualidade enquanto uma esfera positiva da atuação humana (Barzelatto, 1998), que inclui sexo, identidades e papéis de gênero, orientação sexual, erotismo, prazer, intimidade e reprodução (World Healthy Organization WHO, 2002). Nessa conferência, também, surge explicitamente a menção à necessidade da inclusão dos homens neste cenário, justificada por serem sujeitos de direitos sexuais e reprodutivos, e por serem atores fundamentais nas negociações envolvidas neste campo (Figueroa-Perea, 1998).

Em se tratando de investigações que focalizam especialmente a presença dos homens nos processos de saúde sexual e reprodutiva, pode-se identificar que seu início deu-se em torno dos anos 80 , em razão de duas questões principais. Uma delas refere-se ao aumento da epidemia da AIDS, sobretudo nos grupos de mulheres 
casadas, e a outra, à constatação do papel dos homens na regulação da fecundidade de suas parceiras (Villa, 2001).

No âmbito das populações jovens brasileiras, esta situação mostra-se particularmente importante, na medida em que os indicadores do Ministério da Saúde (2002b) a respeito da saúde do adolescente, envolvendo situações de risco em geral e, sobretudo, as taxas de gravidez e Dsts/Aids demonstram a necessidade urgente de investigações que aprofundem o entendimento de como/porque/para que os adolescentes estabelecem determinadas formas de ação no mundo. Estas ações, associadas a todo um conjunto de aspectos de ordem micro e macrossocial, configuram uma situação de vulnerabilidade social absolutamente preocupante no que diz respeito às expectativas quanto ao futuro desta geração. Entende-se por vulnerabilidade um conjunto de elementos de ordem social, político-institucional e comportamental, associados às diferentes suscetibilidades de indivíduos, grupos populacionais e até mesmo nações (Ayres, Calazans \& França Jr., 1998), o que vem ao encontro de uma perspectiva que entende o sujeito como constituído na e pela diversidade.

Destaca-se neste campo o já mencionado artigo de Rios e cols. (2002), uma vez que constitui um estado da arte dos trabalhos de pesquisa e de intervenção voltados para a saúde sexual e reprodutiva dos jovens brasileiros. Segundo os autores, a preocupação com a infecção pelo HIV e com a gravidez na adolescência de fato vem constituindo um foco de atenção de pesquisadores e profissionais da saúde. Reconhecem, no entanto, que do ponto de vista das abordagens ainda se verifica uma concentração de trabalhos voltados para as jovens (Sociedade Civil de Bem-Estar Familiar no Brasil - BEMFAM, 1999; Camarano, 1998; Diaz \& Diaz, 1999; entre outros), a despeito da produção de trabalhos que indicam a necessidade da inclusão dos homens nas análises (Arilha, 1999; Arilha \& Calazans, 1998; Heilborn, 1998; Leal \& Fachel, 1999; Lyra, 1997, 1998, entre outros).

Neste contexto, Camarano (1998) e Heilborn (1998) apontam a possibilidade da existência de sentidos diversificados atribuídos à gravidez e ao exercício da sexualidade na adolescência, variando de acordo com a origem de classe, escolaridade, tradições culturais e religiosas, redes de apoio, entre outros aspectos. Nesta direção, investigações oriundas do campo da Psicologia, que busquem identificar os sentidos atribuídos aos fatos da vida sexual e reprodutiva, podem auxiliar sobremaneira a compreensão do quadro geral indicado aqui relativo ao aumento das taxas de gravidez e de contaminação pelo HIV no âmbito das populações jovens brasileiras. Segundo a abordagem histórico-cultural, o processo de constituição do sujeito acontece de forma mediada por meio da apropriação dos significados das relações sociais, produzidos e partilhados na história de seu grupo em contextos de educação formal e informal, de maneira a atribuir sentidos pessoais de acordo com suas vivências singulares (Vygotsky, 1995). Assim, as práticas sexuais e a própria moral sexual são constituídas/ constituintes pelos/dos sujeitos em suas relações no mundo, não podendo ser analisadas à revelia de seus contextos de significação.

\section{Método}

\section{Participantes}

Foram entrevistados doze rapazes que se dispuseram voluntariamente a participar da pesquisa, contatados na ocasião da devolução dos resultados obtidos na etapa anterior, nas escolas onde os estudantes investigados estudavam. Com relação à caracterização dos sujeitos entrevistados, identificou-se que a faixa etária variou entre 16 e 19 anos; 11 deles cursavam o segundo ano do nível médio - e apenas um, o terceiro; oito eram naturais de Florianópolis e o restante de municípios do interior de Santa Catarina e do Paraná; a escolaridade dos pais variou entre o analfabetismo (uma mãe) e superior completo (seis pais e quatro mães); apenas um deles não morava com sua família de origem.

Estas considerações acerca das características contextuais dos sujeitos investigados mostram-se importantes em face de duas questões fundamentais. Em primeiro lugar, de acordo com a abordagem teórico-metodológica que sustenta este trabalho, entende-se a pessoa como "membro de um grupo social específico, uma unidade social definida, em ser em si para os outros e - para si" (Vygotsky, 1989, p. 64), e, portanto, torna-se imperioso conhecer seu contexto de origem; e, em segundo lugar, há resultados de pesquisas que indicam a existência de relação entre o nível de escolaridade dos jovens e de seus pais, bem como de sua origem de classe, com o uso concreto e correto das informações que detêm sobre métodos contraceptivos e preventivos de Dsts/ (Afonso, 2001; BEMFAM, 1999, entre outras).

\section{Entrevista}

$\mathrm{Na}$ impossibilidade de investigar diretamente as ações dos jovens no campo da sexualidade e da reprodução, uma vez que inscritas na vida privada de cada sujeito, optou-se pelo recurso da obtenção do discurso sobre essas questões e, baseados nele, investigar as significações atribuídas aos fatos da vida sexual e reprodutiva. Considerando que o objetivo era o de aprofundamento das questões investigadas na primeira etapa através de questionário, elaborou-se um roteiro de entrevista semi-estruturada com questões geradoras que se desdobraram no contexto de cada encontro, 
organizadas em blocos temáticos conforme sugerido pela Organização Mundial de Saúde (WHO, 2002) para pesquisas no campo da saúde reprodutiva com populações jovens.

Entrevistar homens na faixa dos 15 aos 19 anos, focando a vida sexual e reprodutiva, revelou-se um desafio que se iniciou pela dificuldade em encontrar jovens nesta faixa etária dispostos a participar. Esta dificuldade pareceu, em um primeiro momento, confirmar a idéia que circula no imaginário social de que os homens não têm o hábito de falar sobre si mesmos e não se dispõem, como as mulheres, a compartilhar sua intimidade com outras pessoas. No entanto, a realização das entrevistas com aqueles que se dispuseram a falar mostrou uma outra situação, as entrevistas foram razoavelmente longas (em média uma hora) e ricas em informações detalhadas. A análise categorial foi feita $a$ posteriori, longitudinal e transversalmente de maneira a ser possível identificar pontos de aproximação e/ou discordâncias entre os sujeitos.

\section{Discussão dos Resultados}

\section{Família de origem e representações de gênero}

Neste bloco de questões investigou-se a estrutura e a organização da família de origem, assim como seu funcionamento no que diz respeito à divisão sexual do trabalho e à educação dos filhos segundo as atribuições de gênero. A família de origem, para os adolescentes entrevistados, constitui o núcleo cuidador principal e a fornecedora do sistema fundamental de valores que norteiam suas práticas. Não se quer afirmar aqui que outros sistemas inexistam na vida desses rapazes. O que seus discursos indicam é que os valores que mantêm são, em grande parte, oriundos do grupo familiar. Pode-se ilustrar essa idéia através do depoimento de um dos sujeitos: "Eles [os amigos] pegavam no meu pé, mas eu não queria saber da opinião deles. A opinião principal é dos teus pais e da tua namorada. Eu acho que é o que conta" (Mauro, 16 anos, escola pública).

O pai constitui-se figura de referência e modelo de identificação, como atesta o depoimento:

Eu me espelho muito nele. Tudo o que ele fer na vida dele, fer.pra nós, os três filhos. (...) Ele, quando era pequeno, chegou a vender picolé na rua, vendia jornal, era um guri de rua. (...) Antigamente ele não tinha nada. Tinha uma bicicleta. Por isso eu me espelho nele. (Diego, 17 anos, escola privada)

O pai aparece nos depoimentos, sobretudo como aquele que provê a família. Aliadas à função de provedor, surgem, também, as de referência moral, de Psico-USF, v. 8, n. 2, p. 203-211, Jul./Dez. 2003 educador, de protetor e, menos expressivamente, de cuidador (considerando-se os cuidados usualmente relacionados à maternagem). Apenas um desses adolescentes não conviveu mais intensamente com seu pai, em razão da separação do casal, e, ainda hoje, mora com a mãe e a irmã.

A mãe é vista como a principal responsável pela educação dos filhos. É a mãe quem cuida, educa, acompanha e conversa, ainda que exerça alguma atividade extradoméstica remunerada. A divisão sexual do trabalho nas famílias de origem mantém-se atribuindo tarefas e funções distintas ao pai e à mãe. Segundo um dos rapazes: "A minha mãe cuidava de casa e meu pai trabalha fora, né? Até hoje ainda. Dona de casa, a minha mãe" (Eduardo, 18 anos, escola pública).

No entanto, surge com maior destaque entre os estudantes da rede privada um outro arranjo, conforme atesta o seguimento trecho: "Cada um tem o seu trabalho [pai e mãe], os dois ajudam em casa" (Diego, 17 anos, escola privada). É também um estudante da rede particular de ensino que, embora indique uma aparente igualdade em termos de trabalho assalariado dos pais e das tarefas domésticas (todos fazem tudo), demonstra uma diferenciação quanto ao destino do salário de cada um:

Lá em casa é tudo muito igual, meus pais trabalham cada um em dois serviços. (...) A única divisão que tem é que o salário do meu pai paga o carro e faz as compras. Minha mãe compra as, digamos... as besteiras da casa. (...) Sempre assim, meu pai sempre paga o que é necessário e minha mãe sempre, sabe, gasta com bobagem, compra coisa nova. (Lucas, 16 anos, escola privada)

Embora, no caso acima relatado, haja a contribuição de ambos - pai e mãe - para o sustento do grupo familiar, a provisão mantém-se sob o encargo do pai. A mãe, na visão deste jovem, parece contribuir com a aquisição de artigos secundários, perpetuando-se aqui a idéia de que o salário da mulher é uma contribuição.

Ao lado disso, há indícios de uma orientação diferente quando se trata da atribuição de tarefas aos filhos - homens e mulheres. Segundo esses jovens, eles são chamados a colaborar nas atividades domésticas, ainda que tal situação não se constitua uma unanimidade no grupo investigado, parecendo prevalecer nas unidades familiares com menor poder aquisitivo e na ausência de uma figura feminina que se responsabilize pela tarefa. Assim diz um deles:

Meu pai estava pintando a casa. (...) Daí eu fui pintar de novo, dai meu pai deu um tempo, foi fazer o almoço. Daí, quando meu pai voltou, eu fui acabar de 
fazer o almoģo. Ai meu irmão acordou tarde, botou a mesa. Então, né, cada um far. um pouco. (Lucas, 16 anos, escola privada)

No caso dos estudantes da rede pública, a delegação de tarefas aos filhos fica mais evidente, como atesta este depoimento:

Minha mãe sempre, até hoje ela divide ainda, só que agora que a minha irmã tá grávida ela não pode fazer muita coisa (...) Ai ela fazia assim: "André faz. tal coisa, Alex faz tal coisa, Juliana tal coisa”. Ai ela marcava lá o que a gente podia fazer, ai a gente dividia. Porque tinha um que lavava calçada, tinha outros que lavava a louça, tinha dia que lavava o fogão, ai dependia do dia, a gente dividia. (André, 18 anos, escola pública)

Quanto à educação de filhos e filhas, embora alguns afirmem não haver distinção na educação entre irmãos e irmãs, esta diferenciação aparece claramente, sobretudo quanto às saídas noturnas: "Meu pai não deixava ela sair mesmo. Eu saio. Meu pai, ele é bem assim, machista" (Rodrigo, 16 anos, escola privada). No grupo dos estudantes da rede pública, esta desigualdade mostra-se ainda mais evidente. Ao compararem a própria educação com a de suas irmãs, lembravam que a rua era um espaço mais permitido para eles do que para elas. As meninas, disseram, eram criadas mais dentro de casa, meninos mais na rua. Um deles, inclusive, traz deste tipo de educação diferenciada a justificativa para o fato de o homem ser "mais assanhado".

A família também se mostra importante no diálogo sobre a sexualidade. Mencionam os amigos como interlocutores nesta área, mas destacam especialmente os pais, sendo irmãos e irmãs citados com menor ênfase. Afirmam, com exceção de um deles, ter uma conversa aberta no espaço familiar. No entanto, pode-se identificar que o diálogo em geral é estabelecido com a mãe, apenas um jovem tendo citado o pai como interlocutor. A mãe, além de cuidadora, é a conselheira e aquela a quem recorrem mais facilmente no âmbito familiar, quando enfrentam algum problema.

Quanto ao pai, o seguinte depoimento resume a situação da maioria deles: "Dificilmente ele pegou um filho assim e chamou: 'Oh vem cá, vou conversar e vou te explicar o que é isso ou o que que é aquilo'. Nunca falou de sexualidade com nós" (Maurício, 18 anos, escola pública). É importante destacar que dois deles não convivem com o pai cotidianamente, um em razão da separação dos pais e, o outro, desde que passou a morar sozinho. Além disso, todas as organizações familiares obedecem ao padrão nuclear, com exceção de uma, que pode ser classificada como monoparental.
Quatro mães têm nível superior de escolaridade e a maioria exerce atividade remunerada. Ainda assim, a divisão sexual do trabalho na família mantém-se de acordo com o modelo tradicional: pai-provedor, mãecuidadora. É possível pensar, portanto, que do ponto de vista dos valores e significações apreendidos no âmbito da família de origem, estes jovens ainda mantêm os padrões tradicionais que diferenciam fortemente as atribuições de gênero.

\section{Relações com os pares}

A relação com os amigos é relatada com um misto de admiração e crítica. O distanciamento crítico aparece, sobretudo, quando os adolescentes referem comportamentos alheios que não julgam adequados. Os amigos são considerados aqueles com os quais são compartilhados gostos, valores e, em especial, programas de lazer. Amigos têm

Os mesmos gostos, as mesmas paradas. Tem muito camarada meu que "ah, vamos sair, fazer um esporro, quebrar tudo". Acho isso ai nada a ver, pra quê isso? Os que eu considero mais camarada meu são quase que nem eu, "ah, vamos sair pra curtir". São poucos. Tem muitos que são ignorantes. (Diego, 17 anos, escola privada)

Chama a atenção na fala de Diego o trecho: "são quase que nem eu". É importante considerar aqui os movimentos de identificação e diferenciação que fazem parte do processo de constituição do sujeito. Mesmo no grupo de convívio há aqueles dos quais se diferencia de maneira contrastiva e valorativa na medida em que critica sua proposta: os "ignorantes". Por outro lado, identifica-se com aqueles que "curtem" de forma semelhante à dele que, segundo ele, são "poucos".

Os amigos servem também de referência para que possam verificar se as mudanças que ocorreram na puberdade são comuns a todos: "Conversava com meus amigos, para ver se estava acontecendo a mesma coisa" (Márcio, 16 anos, escola privada), e, "Em São Lourenço, quando eu era assim novo, tinha eu e um colega meu, a gente tava sempre cuidando 'ah, ta nascendo pelinho..." (Maurício, 18 anos, escola pública).

A necessidade de conferir com os pares se se é igual (o espelho) e, portanto, se não há qualquer anormalidade no que está acontecendo, parece marcante. Neste caso, a família já não é a referência. Outro sujeito de idade semelhante, do mesmo gênero, funciona como aquele que atesta a "normalidade" das mudanças corporais na puberdade, com o qual se compartilha as novidades e as inseguranças a este respeito. 


\section{Sexualidade e gênero}

De todos os doze sujeitos entrevistados, apenas um trouxe em seu discurso concepções e práticas mais igualitárias de gênero. Afirmou que homens e mulheres devem ter os mesmos direitos, incluindo as questões relativas à sexualidade (iniciativa quanto à abordagem sexual/amorosa e uso do preservativo, por exemplo). No entanto, como os outros, fez referências ao que chamou de vulgaridade como algo a ser evitado no comportamento das mulheres. A vulgaridade feminina parece ser definida, entre outros critérios, pelo fato da mulher aceitar ter relação sexual no primeiro encontro: "Assim como ela fez comigo, ela vai fazer com outro também" (André, 18 anos, escola pública). Gabriel comenta a mudança no comportamento das mulheres, atribuindo juízo de valor ao que considera, nos dias de hoje, como a vulgarização e a desqualificação femininas:

Porque a mulher hoje em dia, como é que eu vou te explicar... a mulher tem se vulgarizado muito. (...). Eu acho que está muito fácil o acesso às mulheres hoje em dia. Mais fácil do que antigamente, claro. Antigamente era nos bordéis que se encontravam as mulheres. Era mais fechado, não era como é hoje. A mulher está perdendo o valor mesmo. (Gabriel, 17 anos, escola particular)

Mesmo entre o grupo dos estudantes da rede privada de ensino, oriundos das camadas médias e com pais de nível superior de escolaridade, as representações de gênero permanecem conservadoras. Poder-se-ia esperar, neste grupo, a presença mais marcante do modelo igualitário (Duarte, 1987; Heilborn, 1998; Salem, 1989, entre outros). No entanto, suas falas demonstram, sobretudo no campo da sexualidade, a manutenção de padrões tradicionais que diferenciam as mulheres dos homens com relação ao comportamento sexual e classificam as últimas de acordo com critérios morais rígidos: "Eu acho assim (...) uma guria que, assim, tu tá passando na rua e ela chega em ti, boa coisa não deve ser" (Diego, 17 anos, escola privada). Ou ainda,

\section{A educação do menino e da menina é bem} diferente. As meninas fazem mais jogo duro, são mais reservadas. Os guris são mais atirados. "Ah, vamos sair para agarrar um monte." As gurias já não, têm que escolber o cara certo. (Márcio, 16 anos, escola privada)

Fica evidente, também, a diferenciação que efetuam entre "ficar" e "namorar". Ficar é "nada sério", "agarrar aqui, esquecer e já agarrar outra ali". Ainda que ficar seja um termo relativamente novo, uma vez que surge a partir dos anos 80 (Rieth, 1998), estes rapazes observam mudanças no tempo histórico mais recente dizendo que "o ficar de agora ficou uma coisa mais íntima". O namoro, por outro lado, foi definido como algo mais sério, envolvendo mais compromisso, responsabilidade, segurança e associado a sentimentos como confiança na parceira e gostar muito dela. Dois dos sujeitos fazem uma diferenciação entre os tipos de namoro. Um deles ressaltou o uso de aliança de compromisso como promotora de segurança no relacionamento. Já o outro declarou que um namoro menos compromissado seria ter "uma namorada sem muita família". Apesar da seriedade do relacionamento estar simbolizada de diferentes maneiras nos dois casos, nota-se que ambos se referem ao torná-lo mais público, envolvendo familiares e amigos, uma etapa que eles apenas alcançam quando pretendem um compromisso mais sério. $\mathrm{Na}$ realidade, o que afirmam atesta o que Rieth (1998) concluiu, indicando que o namoro projetase no futuro como uma relação estruturada, reconhecida pelos pais e pela rede de amigos. Freqüentemente vem associado às idéias de compromisso e respeito que se baseiam em um vínculo de fidelidade e confiança; é o lugar do sentimento, em contraste como o do interesse sobretudo físico que caracteriza o ficar.

Dentre os doze entrevistados, apenas dois não haviam se iniciado sexualmente. Todos os outros tiveram sua primeira relação sexual entre os 14 e os 16 anos, com a namorada ou "ficante" (como denominam) ou prima. Há dados de outras pesquisas que indicam exatamente estas categorias de parcerias como as predominantes na iniciação sexual nos tempos contemporâneos, não apenas no caso brasileiro (BEMFAM, 1999; WHO, 2002).

Todos eles mencionaram práticas referentes às preliminares da relação sexual, bem como a preocupação com a garantia do próprio prazer e da satisfação da parceira. Alguns afirmam a importância do carinho e da atenção para que a relação sexual seja bem sucedida, ainda que enfatizem a atração física forte. A espera pelo momento adequado da parceira para que a relação ocorra também foi mencionada. Admitem, ainda, que há outras formas de se obter prazer sexual que não remetam apenas à relação no sentido restrito, dentre elas a masturbação e outras formas de carícias a dois.

O seguinte depoimento, no entanto, atesta o caráter organicista atribuído à relação sexual, que parece predominar entre eles:

É normal ter uma necessidade sexual, o corpo pede isso. Se não tiver um relacionamento com uma mulher tu vais se masturbar ou coisa parecida. (...) Uma mulher que já teve uma relação, se ela ficar muito tempo sem ter, acho que sente falta sim, com certeza sente falta. (Maurício, 18 anos, escola pública) 
Chama a atenção, aqui, além da menção ao caráter de necessidade física, o fato de este rapaz ter se referido à mulher já iniciada sexualmente como aquela que sentiria falta, ao passo que não fez esta ressalva com relação aos homens.

Dentre aqueles que já tiveram relações sexuais, um declarou tê-lo feito com um parceiro do mesmo sexo, justificando-se pela curiosidade e afirmando que não pretende manter esta prática. Dos demais, apenas um não se manifesta contrário à homossexualidade. Todos os outros consideram-na algo da ordem da anormalidade. O incômodo com relação à possibilidade de convívio com homossexuais é claramente explicitado por um deles. A atribuição de causalidade também é mencionada: "porque são feios e gordinhos e não conseguem mulheres", "porque está muito fácil conseguir mulher hoje em dia e eles buscam uma coisa nova", "porque perderam a atração por mulheres", "por opção", "por fatores psicológicos". De qualquer maneira, para esses rapazes o normal é ser heterossexual e, no caso dos homens, viril.

\section{Uso do preservativo, Dsts/Aids e gravidę, na adolescência}

Todos afirmam usar o preservativo em seus relacionamentos, não sendo esta, no entanto, uma prática constante. Não houve consenso quanto ao uso da camisinha quando a parceira é uma namorada, sendo a confiança uma palavra-chave para explicação de tal situação. Atrelado a isso, o não-uso também apareceu justificado pelo fato da parceira já tomar pílula anticoncepcional, liberando-os da preocupação maior: a gravidez. Com isso, demonstraram considerar que o conhecimento que tinham da parceira assegurava-lhes de que ela permaneceria numa relação de exclusividade com eles e desconsideraram que, anteriormente, ela pudesse ter vivenciado alguma situação de risco diante das Dsts/Aids. Segundo essa lógica, conhecendo a parceira e nela confiando, restava, então, a proteção contra a gravidez indesejada: "É, mas nem tanto pela Aids, mais pela gravidez, né? Porque eu conhecia muito bem ela, ela me conhecia também" (Eduardo, 19 anos, escola pública).

Questiona-se aqui o que consideram, então, conhecer a parceira. Este mesmo rapaz relatou que, nas negociações para uso da camisinha, costuma explicar sobre a importância da prevenção, alertando para a possibilidade "de que uma doença esteja encubada nela (parceira) e que ela não saiba". Ainda que tenha reconhecido a possibilidade de latência de alguma infecção, destaca-se, dessa última fala, o trecho "ela não sabe" que denuncia a fragilidade do que considera conhecer o outro, quando se admite que este outro pode não se conhecer por completo ou o suficiente.

Lucas coloca a questão da confiança e da fidelidade como aspectos que justificam o não-uso do preservativo afirmando que:
Nesse aspecto vale a fidelidade e a confiança. Se eu não fosse fiel a ela, en ia querer usar sempre e en ia saber que o risco era grande. Se eu não confiasse nela, eu também iria querer usar sempre, porque eu saberia que também tinha risco muito grande. (Lucas, 16 anos, escola privada)

André, embora reconheça que o uso do preservativo diminua o prazer na relação sexual, resumiu o não-uso em uma única e clara justificativa:

\section{Uns dizem que dá desconforto, outros dizem que} tira o prazer, outros que porque não deu tempo, ai en acho que é mais, que é mais... porque não querem fazer mesmo com camisinha, sabe? Não quer fazer e não faz mesmo com camisinha, ai tem que inventar alguma coisa. (André, 18 anos, escola pública)

Fica evidente que ele considera as justificativas presentes no discurso dos adolescentes como explicações acobertadoras do principal motivo para o não-uso da camisinha: a falta de vontade. De qualquer maneira a negociação para o uso da camisinha nem sempre é fácil para esses rapazes. Segundo eles, a parceira pode pensar que desconfiam dela, a "menosprezam" (sic). Curioso que nenhum deles mencionou a possibilidade dela colocar sob suspeita a fidelidade dele. Também não indicaram como justificativa para o uso inconstante do preservativo a falta ou a limitação de informações, bem como a dificuldade em obtê-lo. Ao contrário, todos afirmam que há informação suficiente sobre as formas preventivas e que $\mathrm{O}$ acesso ao preservativo é fácil. Apenas um deles sugere que a distribuição seja mais facilitada e que as políticas públicas voltem-se especialmente para os jovens que ainda estão iniciando a vida sexual, como forma de possibilitar o desenvolvimento de novos hábitos.

Quando questionados sobre o que sabiam a respeito das Dsts/Aids, onde obtinham informações e quais conheciam, citavam doenças como sífilis, gonorréia e, sobretudo, a própria Aids. Esta última, segundo eles, é a principal preocupação das campanhas preventivas, o que faz com que o conhecimento sobre as demais Dsts fique prejudicado. Afirmaram que aprenderam o que sabem em feiras de ciência, aulas de biologia, propagandas e programas de televisão, livros e revistas, e, também, com os pais. Nenhum deles afirmou já ter tido algum sintoma de qualquer doença sexualmente transmissível, embora conheçam pessoas que tiveram.

A maioria desses rapazes considera a gravidez na adolescência algo a ser evitado. Associam a gravidez nessa etapa da vida com perda, desespero em pensar 
que teriam que "se virar" sozinhos, ignorância, e ressaltam a importância de uma independência e estabilidade financeira para gerar um filho, explicando, desta forma, porque não gostariam de ser pais nessa etapa do ciclo vital. Novamente aparece aqui a atribuição da função de provedor ao pai: "Porque antes de amor, tu tens que dar comida, tens que dar conforto, tens que dar tudo" (Lucas, 16 anos). O adolescente não pode ser pai porque não pode prover. Além disso, não teria experiência suficiente para educar um filho. A perda de privilégios na família, bem como da possibilidade de ir e vir com os amigos, é outro motivo apontado pelos jovens para evitarem filhos na adolescência.

A gravidez na adolescência é atribuída à irresponsabilidade, embora um desses rapazes afirme a possibilidade de escolha do casal sobre ter ou não filhos. Associam a gestação nesta fase à necessidade de afirmação, querer demonstrar maturidade ou ganhar status: "querem se mostrar o machão, até mesmo a guria querer mostrar para os pais e transar, ter filho"; "porque muita gente só engravida para ter um status na vida, principalmente as meninas".

$\mathrm{Na}$ realidade o que estes rapazes apontam é o que Arilha (1998) e Fuller (1997), entre outros, discutem em seus trabalhos: a assunção da paternidade parece configurar a passagem da vida de "descompromisso" do jovem à "responsabilidade" do adulto. Heilborn (1998) insiste, no entanto, que a maternidade/paternidade na adolescência deve ser compreendida em seu contexto de ocorrência, sobretudo no que diz respeito à configuração de valores dos grupos culturais nos quais os adolescentes constituem-se como sujeitos.

Em se tratando de sociedades complexas, coexiste com a ideologia individualista/igualitarista mais visível nas camadas médias urbanas e intelectualizadas, uma configuração holista mais tradicional na qual a família e as relações hierárquicas entre os sexos e as gerações mantêm-se como ordenadoras da vida (mais freqüente nos segmentos populacionais de baixa-renda). Embora se trate apenas de modelos e, obviamente os sujeitos concretos não correspondam a eles em sua forma absoluta, esta metáfora parece útil para se compreender por que nas camadas médias o projeto de vida baseado na realização profissional e financeira individual sobrepõe-se à idéia de projetos familiares. Em contrapartida, nos segmentos de baixa renda, a maternidade e a paternidade podem ser valorizadas como promotoras de status no grupo (Heilborn, 1998).

No caso dos adolescentes, esta complexidade mostra-se ainda mais visível e imperiosa, na medida em que são "filhos", em geral convivendo numa rede familiar e dependentes de seus pais de forma a não terem condições de assumir a responsabilidade pela paternidade, uma vez que incapazes de estar em condições materiais e subjetivas de "formar uma família" (Villa, 1999). Espera-se, portanto, que o adolescente "controle" seus impulsos sexuais, embora espere-se também que não os controle, uma vez que é significado socialmente como irresponsável. Ademais, trata-se de homens que devem mostrar-se viris. A tensão estabelecida entre a concretização desses impulsos - traço visto como masculino - e sua incontrolabilidade, por um lado, e, por outro, a noção moral de responsabilidade parecem traçar um quadro no qual o adolescente vê-se duplamente sujeitado - pela "natureza" e pela moral. Por outro lado, sua assunção à maturidade significa submeter-se ao ditame "conheça a si mesmo" e assuma as conseqüências de suas ações no mundo.

Esse quadro traçado por Villa (1999) parece retratar a situação de vida dos jovens entrevistados que assumem, em seus discursos, a tensão decorrente de matrizes simbólicas diferentes, as mais tradicionais e as igualitárias, com predomínio das primeiras.

\section{Considerações Finais}

Antes de esboçar qualquer conclusão, mesmo que preliminar, é preciso ainda que se resgate o processo de elaboração dos discursos desses jovens que, com alguma freqüência, deixavam transparecer uma reflexão em curso quando falavam. Respondiam inicialmente às questões de uma maneira mais enfática e definida e, aos poucos, iam relativizando suas próprias palavras, inserindo outros aspectos que não tinham anteriormente considerado. Tal situação vem ao encontro da referência vygotskyana, pois, na medida em que o entrevistador lança uma pergunta, ele incita o entrevistado a pensar e, sobretudo, a pensar sobre si. Nesse processo reflexivo e dialético, o sujeito distanciase dele mesmo e se torna outro de si mesmo. A consideração destas questões torna-se importante, entre outros motivos, pela visão corrente no senso comum de que os adolescentes agiriam de maneira irrefletida, impulsiva e não refletiriam de maneira crítica sobre suas próprias ações. Outro ponto que também se contrapõe à visão estereotipada sobre os adolescentes refere-se ao comportamento sexual e reprodutivo dos jovens entrevistados no que diz respeito à manutenção de modelos tradicionais de família, sexualidade e relações de gênero, a despeito de algumas modificações típicas da juventude contemporânea.

Os processos reflexivos desses adolescentes ainda se evidenciaram em momentos nos quais relataram práticas de colegas e amigos dos quais discordavam. Frases como "eu achei sacanagem o que ele fez com a menina..."; “o cara inocente...”; “cada cabeça tem seu guia, mas eu..."; "muitos garotos aí acham... mas eu não vejo assim...”, são apenas algumas 
que podem servir de exemplo. Neste caso, importante também se faz considerar que há uma diferença significativa identificada em todos os discursos quanto ao agente da ação em questão. Quando o agente é o próprio sujeito entrevistado, sua ação (relatada) parece ser beneficiada por um juízo de valor mais condescendente do que quando se refere à de outrem. Pode-se considerar aqui que o sentido atribuído à própria ação é expressivamente distinto do atribuído à do outro, embora sejam ações/práticas semelhantes. Esta não nos parece uma situação exclusiva dos adolescentes, uma vez que a necessidade de diferenciação eu-outro é permanente ao longo da trajetória do sujeito no mundo, em especial quando há implicações afetivas em jogo. Quando o sujeito está diretamente implicado na situação, tende a avaliá-la de maneira diferente do que quando não está.

Se alguns se consideraram bem informados em relação ao uso de preservativo e Dsts/Aids, por outro lado, expressaram dúvidas, especialmente em relação às possibilidades de prática de sexo oral, sem que se corra o risco de ser infectado por uma doença. Nesse sentido, pode-se identificar que a insuficiência de informações mantém-se apesar dos esforços de programas de educação sexual e campanhas preventivas veiculadas pela mídia. Ganha destaque aqui a denúncia feita por um dos entrevistados, apontando a falta de informações dirigidas aos homens em comparação com a grande quantidade fornecida às mulheres. Tal situação demonstra a necessidade de se desconstruir a lógica que sustenta as desigualdades de gênero, tanto no âmbito da cidadania pública, quanto no da cidadania privada.

Outro ponto interessante de ser retomado corresponde aos elementos de ordem subjetiva, que influenciam na decisão de se prevenir ou não ante as Dsts/Aids. Fica nítido, através do material obtido, que a confiança na relação sexual/amorosa torna-se um elemento-chave para a segurança/prevenção entre os parceiros. A confiança, neste caso, nada mais é do que a garantia da fidelidade/exclusividade sexual, o que, como se sabe, não faz com que o risco não esteja presente.

Enfim, é preciso problematizar estes aspectos junto às equipes e programas de saúde sexual e reprodutiva de forma a incluírem estas discussões em suas atividades, auxiliando eficazmente os jovens a exercerem sua vida sexual e reprodutiva de maneira apoiada e segura.

\section{Referências}

Afonso, M. L. (2001). A polêmica sobre adolescência e sexualidade. Belo Horizonte: Campo Social.

Arilha, M. (1998). Homens: entre a "zoeira" e a "responsabilidade". Em M. Arilha, S. G. U. Ridenti, \& B. Medrado (Orgs.). Homens e Masculinidades. (p. 5177). São Paulo: ECOS/Editora 34.

Arilha, M. (1999). Homens, saúde reprodutiva e gênero: o desafio da inclusão. Em K. Giffin \& S. H. Costa (Orgs.). Questões da saúde reprodutiva. (p. 455-467). Rio de Janeiro: FIOCRUZ.

Arilha, M. \& Calazans, G. (1998). Sexualidade na Adolescência: o que há de novo? Em E. Berquó (Org.). Jovens acontecendo na trilha das politicas públicas $v$. 2. (p. 687-712). Brasília: CNPD.

Ayres, J. R. C. M., Calazans, G. J. \& França Júnior, I. (1998). Vulnerabilidade do Adolescente ao HIV/ AIDS. Em E. M. Vieira, M. E. L. Fernandes, P. Bailey \& A. Mckay (Orgs.). Seminário Gravidez na Adolescência. (p. 97-109). Rio de Janeiro: Associação Saúde da Família.

Barzelato, J. (1998). Desde el control de la natalidad hacia la salud sexual y reproductiva: la evolución de un concepto a nivel internacional. Em E. D. Bilac \& M. I. B. Rocha (Orgs.). Saúde reprodutiva na América Latina e no Caribe: temas e problemas. (p. 39-49). Campinas: PROLAB, ABEP, NEPO, UNICAMP.

Camarano, A. (1998). Fecundidade e anticoncepção da população de 15-19 anos. Em E. M. Vieira, M. E. L. Fernandes, P. Bailey \& A. McKay (Orgs.). Seminário Gravidez na Adolescência. (p. 35-54). Rio de Janeiro: Associação Saúde da Família.

Diaz, J. \& Diaz, M. (1999). Contracepção na adolescência. Em N. Schor, M. Mota \& V. C. Branco (Orgs.). Cadernos juventude, saúde e desenvolvimento. (p. 249-257). Brasília: Ministério da Saúde.

Duarte, L. F. (1987). Pouca vergonha, muita vergonha: sexo e moralidade entre as classes trabalhadoras urbanas. Em J. S. Lopes (Org.). Cultura e identidade operária. (p. 203-226). São Paulo: Marco Zero/PROED.

Figueroa-Perea, J. G. (1998). Algunos elementos para interpretar la presencia de los varones en kis procesos de salud reproductiva. Cadernos de Saúde Pública, 14(1), 87-96.

Fuller, N. (1997). Identidades masculinas. Lima: Pontifícia Universidad Católica del Perú.

Heilborn, M. L. (1998). Gravidez na Adolescência: considerações preliminares sobre as dimensões culturais de um problema social. Em E. M. Vieira, M. E. L. Fernandes, P. Bailey \& A. McKay (Orgs.). Seminário Gravidez na Adolescência. (p. 23-32). Rio de Janeiro: Associação Saúde da Família.

Leal, O. \& Fachel, J. (1999). Jovens, sexualidade e estratégias matrimoniais. Em M. L. Heilborn (Org.). 
Sexualidade: o olhar das ciências sociais. (p. 96-116). Rio de Janeiro: Zahar.

Lyra, J. (1997). Paternidade Adolescente: uma proposta de intervenção. (Dissertação de Mestrado). São Paulo: Pontifícia Universidade Católica de São Paulo.

Lyra, J. (1998). Participação masculina na gravidez adolescente. Em E. M. Vieira, M. E. L. Fernandes, P. Bailey \& A. Mckay (Orgs.). Seminário Gravidez na Adolescência. (p. 119-126). São Paulo: Associação Saúde da Família.

Matamala, M. I. (1998). Derechos sexuales y reprodutivos, Estado y Sociedad. Em E. D. Bilac \& M. I. B. Rocha (Orgs.). Saúde reprodutiva na América Latina e no Caribe: temas e problemas. (p. 237-260). Campinas: PROLAB, ABEP, NEPO, UNICAMP.

Ministério da Saúde. (2002a). Informações de Saúdel DATASUS. Brasília: Autor.

Ministério da Saúde. (2002b). Programa de Saúde do Adolescente. Brasília: Autor. <http//:www.saude.gov.br/sps/ areastecnicas/adolescente/home.htm $>$.

Rieth, F. (1998). Ficar e namorar. Em C. Bruschini \& H. B. Hollanda (Orgs.). Horizontes plurais: novos estudos de gênero no Brasil. (p. 11-133). São Paulo: Fundação Carlos Chagas/Editora 34.

Rios, L. F., Pimenta, C., Brito, I., Terto Júnior, V. \& Parker, R. (2002). Rumo à adultez: oportunidades e barreiras para a saúde sexual dos jovens brasileiros. Cadernos CEDES, 22(57), 45-61.
Salem, T. (1989). Casal igualitário: princípios e impasses. Revista Brasileira de Ciências Sociais, 3(9), 24-37.

Sociedade Civil de Bem-Estar Familiar no Brasil BEMFAM. (1999). Adolescentes, jovens e a pesquisa nacional sobre demografia e saúde. Um estudo sobre fecundidade, comportamento sexual e saúde reprodutiva. Rio de Janeiro: Autor.

Villa, A. M. (2001). Presencias masculinas en las opciones reproductivas: significados en mujeres y varones jovenes de sectores urbanos medios y pobres (relatório de pesquisa). Buenos Aires.

Villa, A. M. (1999). Sexualidad, Reproduccion y Paternidad: una introduccional analisis de la demanda social en las relaciones de genero. Em D. P. Marques da Silva (Org.). Novos contornos no espaço social: gênero, geração e etnia. (p. 7-22). Rio de Janeiro: UERJ, NAPE.

Vygotsky, L. S. (1989). Pensamento e Linguagem. São Paulo: Martins Fontes.

Vygotsky, L. S. (1995). Obras Escojidas III. Madrid: Visor.

World Healthy Organization - WHO. (2002). Sample Core Instruments. Disponível em < http:/ / www.who.int/ reproductive-health/adolescent $>$

Recebido em janeiro de 2003 Reformulado em novembro de 2003 Aprovado em dezembro de 2003

Sobre as autoras:

Maria Juracy Filgueiras Toneli é psicóloga, doutora em Psicologia, professora adjunta da Universidade Federal de Santa Catarina, pesquisadora do CNPq e coordenadora do Programa de Pós-Graduação em Psicologia da UFSC.

Thais Guedes é psicóloga e foi bolsista de pesquisa do CNPq/PIBIC/UFSC, com projeto sobre a sexualidade na adolescência, enfocando a figura masculina.

Daniela Mendes é psicóloga e foi bolsista IC/CNPq, com projeto de pesquisa em sexualidade na adolescência, com ênfase na constituição da masculinidade e da paternidade.

Ivana Finkler é psicóloga e foi bolsista CNPq/PIBIC/UFSC, com projeto sobre a sexualidade na adolescência.

Mariana Barreto Vavassori é aluna do curso de Psicologia da Universidade Federal de Santa Catarina e bolsista $\mathrm{CNPq} / \mathrm{PIBIC} / \mathrm{UFSC}$. 
